\title{
SEVERIDADE DE ISOLADOS DE Fusarium subglutinans f. sp. ananas SENSÍVEIS E RESISTENTES AO BENOMYL, EM ABACAXIZEIRO
}

\author{
BIVANILDA A. SANTOS ${ }^{1}$, LAÉRCIO ZAMBOLIM ${ }^{1,}$ JOSÉ A. VENTURA $^{2}$ \& FRANCISCO XAVIER R. VALE ${ }^{1}$
}

${ }^{1}$ Departamento de Fitopatologia da Universidade Federal de Viçosa, 36571-000, Viçosa, MG, e-mail: zambolim@ufv.br; ${ }^{2}$ Instituto Capixaba de Pesquisa e Extensão Rural, Cx. Postal 391, 29010-901, Vitória, ES

(Aceito para publicação em 08/10/2001)

Autor para correspondência: Laércio Zambolim

SANTOS, B.A., ZAMBOLIM, L., VENTURA, J.A. \& VALE, F.X.R. Severidade de isolados de Fusarium subglutinans f. sp. ananas sensíveis e resistentes ao benomyl em abacaxizeiro. Fitopatologia Brasileira 27:101-103. 2002.

\section{RESUMO}

Mudas das cultivares de abacaxi (Ananas comosus) 'Pérola' (suscetível) e 'Primavera' (resistente) foram inoculadas em casa de vegetação com isolados de Fusarium subglutinans f. sp ananas, resistentes e sensíveis ao benomyl, de diferentes áreas produtoras de abacaxi do Espírito Santo, visando estudar a virulência do patógeno. Foi utilizada suspensão de conídios obtidos pela raspagem da superfície das colônias desenvolvidas em meio BDA, cuja concentração final foi $10^{5}$ conídios/ml. A inoculação de $F$. subglutinans f. sp ananas foi efetuada pela imersão de mudas injuriadas mecanicamente na base, com três meses de idade, na suspensão de inóculo. Dos 22 isolados testados preliminarmente, selecionou-se oito de F. subglutinans f. sp ananas, sendo quatro representativos do grupo dos sensíveis ao benomyl (E285, E277, E278 e E290) e quatro representativos do grupo dos resistentes ao benomyl (E272, E274, E279 e E283) para realização do teste final. Os resultados comprovaram a resistência da cv. Primavera a todos os isolados testados. Plantas da cv. Pérola apresentaram sintomas da doença aos 15 dias após a inoculação com isolados resistentes ao benomyl; os isolados sensíveis ao benomyl só foram capazes de causar sintomas severos da doença aos 45 e 60 dias após a inoculação. O isolado E272, resistente ao benomyl, foi o mais virulento, tendo causado a maior lesão e a morte das plantas aos 30 dias após a inoculação; os isolados E277 e E278 foram os mais virulentos. Houve diferenças em virulência de isolados de $F$. subglutinans f. sp. ananas resistentes e sensíveis ao benomyl ao abacaxizeiro.

Palavras-chave adicionais: Ananas comosus, fusariose, resistência, benomyl.

\section{ABSTRACT \\ Severity of isolates of Fusarium subglutinans f. sp. ananas resistant or not to benomyl on pineapple}

Out of 22 isolates of Fusarium subglutinans f. sp. ananas tested in preliminar trials, it was selected for the final experiment four isolates representing the resistant group (E272, E274, E279 e E283), and four representing the susceptible group (E285, E277, E278 e E290) of Fusarium subglutinans f. sp. ananas to benomyl. The isolates were collected on diseased pineapple plants from the southern area of the Espírito Santo State, and inoculated on three months old pineapple (Ananas comosus) seedlings, cv. Perola (susceptible) and Primavera (resistant), under greenhouse conditions, to study the virulence of the pathogen. The pineapple seedlings were inoculated by immersion of the seedlings in a conidial suspension $\left(10^{5}\right.$ conidia/ml) scratched from PDA plates, after they had been injured on their crown area. The results showed that the cv. Primavera was resistant to all isolates tested. The cv. Perola showed symptoms of fusariosis 15 days after the inoculation with the isolates resistant to benomyl. The isolates susceptible to benomyl caused symptom of the disease 45 days after the inoculation. The isolate E272 (resistant to benomyl) was the most virulent isolate to cv. Perola, whereas the isolates E277 and E278 (susceptible) to benomyl were the least virulent. The susceptible isolates to benomyl caused symptoms of the disease on the cv. Perola 45 and 60 days after the inoculation. In conclusion this study showed that there are differences in virulence between the isolates of $F$. subglutinans f. sp. ananas resistant and susceptible to benomyl to pineapple.
Dentre todas as doenças do abacaxizeiro (Ananas comosus L.), a fusariose destaca-se por ser a que maiores prejuízos econômicos traz aos produtores, uma vez que as perdas podem atingir até $100 \%$ da produção. No Brasil, as duas cultivares mais plantadas são a 'Pérola' e a 'Smooth Cayenne', ambas suscetíveis à doença constituindo base genética estreita, dificultando os programas de melhoramento (Giacomelli, 1974; Py, et al. 1984). A doença, relatada pela primeira vez por Kimati \& Tokeshi (1964) no estado de São Paulo em frutos da cultivar 'Smooth Cayenne', atual- mente já se encontra disseminada por todo o país e em alguns países da América Latina. Os sintomas mais característicos da doença são alterações morfológicas das plantas doentes, bem como exsudação de goma ou resina, daí a doença ser conhecida, inicialmente, por gomose (Pissarra et al., 1979). $\mathrm{O}$ agente etiológico é o fungo Fusarium subglutinans (Wollenweber \& Reinking) Nelson, Toussoun \& Marasas f. sp. ananas Ventura, Zambolim \& Gilbertson que apresenta especificidade para o abacaxizeiro (Ventura et al., 1993a; Ventura et al., 1994; Ventura, 1996). Para o controle da 
doença recomenda-se a integração de medidas que incluem o plantio de material propagativo sadio, a erradicação de plantas doentes, a eliminação dos restos culturais, a uniformização da indução floral e o controle químico com fungicidas durante a antese (Ventura et al., 1993b). O uso constante do fungicida sistêmico benomyl para o controle da doença tem induzido o aparecimento de isolados do fungo resistentes (Ventura et al. 1994; Santos, 2000), comprometendo o uso deste fungicida no controle da doença. O uso de cultivares de abacaxi resistentes é uma das alternativas mais viáveis para o controle da doença (Matos \& Cabral, 1988; Matos et al., 1991). Cabral et al. (1985) identificaram as cultivares 'Pérolera' e 'Primavera' como fontes de resistência para programas de melhoramento, tendo o Centro Nacional de Pesquisa de Mandioca e Fruticultura, em Cruz das Almas-Bahia recomendado o seu uso em áreas onde a doença é endêmica (Ventura et al., 1994). O desenvolvimento de programas de melhoramento visando resistência genética a uma determinada doença, requer o conhecimento prévio da variabilidade genética do patógeno. Portanto, o presente trabalho foi desenvolvido com o objetivo de estudar a severidade de isolados de F. subglutinans f. sp. ananas resistentes e sensíveis ao benomyl, nas cultivares 'Pérola' (suscetível) e 'Primavera' (resistente) ao patógeno.

Vinte e dois isolados do patógeno foram coletados inicialmente de plantas suscetíveis (cvs. Pérola e Smooth Cayenne) a fusariose, de regiões produtoras de abacaxi do Estado do Espírito Santo. Após a realização de testes preliminares de patogenicidade na cv. Pérola, selecionaramse oito isolados de F. subglutinans f. sp ananas sendo quatro sensíveis ao benomyl, denominados E285, E277, E278 e E290 e, quatro resistentes, denominados E272, E274, E279 e E283, que foram armazenados em tubos de cultura contendo BDA à temperatura de $5{ }^{\circ} \mathrm{C}$. Os 22 isolados do patógeno foram obtidos pelo método indireto, plaqueando fragmentos do tecido doente de mudas de abacaxizeiro das cultivares 'Pérola' e 'Smooth Cayenne'. Os segmentos de tecidos lesionados foram inicialmente desinfestados superficialmente por imersão (23 min) em solução de hipoclorito de sódio a $2 \%$ e transferidos para meio semi-seletivo constituído de $15 \mathrm{~g}$ de peptona, $1 \mathrm{~g}$ de $\mathrm{KH}_{2} \mathrm{PO}_{4}, 0,5 \mathrm{~g}$ de $\mathrm{MgSO}_{4} . \mathrm{H}_{2} \mathrm{O}, 1 \mathrm{~g}$ de pentacloronitrobenzeno (PCNB 75\%), $20 \mathrm{~g}$ de agar e 11 de $\mathrm{H}_{2} \mathrm{O}$. O meio foi previamente autoclavado e quando a temperatura atingiu $45^{\circ} \mathrm{C}$, adicionaram-se $200 \mathrm{mg}$ de cloranfenicol e 200 $\mathrm{mg}$ de sulfato de estreptomicina. Após repicagem para placas de Petri os fungos foram incubados a $25{ }^{\circ} \mathrm{C}$ no fotoperíodo diário de $12 \mathrm{~h}$ por 15 dias. Os isolados obtidos foram avaliados quanto à resistência ao fungicida benomyl, determinando-se a $\mathrm{DL}_{50}$ para a germinação dos conídios e para o crescimento micelial de acordo com Santos (2000). Os isolados resistentes a até $1.000 \mu \mathrm{g} \cdot \mathrm{ml}^{-1}$ de benomyl foram selecionados para este trabalho, comparando-os com isolados de F. subglutinans f. sp. ananas sensíveis. Foram utilizadas mudas do tipo filhote, com três meses de idade, das cultivares 'Pérola' e 'Primavera' provenientes da INCAPER. O experimento foi conduzido em casa-de-vegetação, onde as mudas foram cultivadas em vasos de plástico com capacidade para $2 \mathrm{~kg}$, contendo a mistura de solo e areia (4:1) v/v. O delineamento experimental utilizado foi inteiramente casualizado, com cinco repetições, tendo cada repetição dez mudas. A irrigação das plantas foi feita sempre que necessária e a adubação realizada a cada 30 dias com NPK, conforme recomendação para a cultura. Para a inoculação foi utilizada uma suspensão de conídios obtidos da raspagem da superfície das placas com crescimento do fungo, cuja concentração final foi ajustada para $10^{5}$ conídios. $\mathrm{ml}^{-1}$, utilizando-se câmara de Neubauer. A inoculação das mudas foi efetuada pela imersão na suspensão de inóculo, após injúria mecânica na base, realizada com o auxílio de um dispositivo de 60 agulhas entomológicas (Ventura et al., 1994). Após 90 dias, realizou-se o arranquio e a avaliação dos sintomas internos na base das mudas inoculadas por meio da mensuração do tamanho da lesão em relação ao local de inoculação, bem como a adoção de um sistema de escala de notas de 1 (um) a 6 (seis), onde $1=$ sem sintoma interno; $2=$ início de podridão; $3=$ podridão leve; $4=$ podridão média; 5 - podridão severa, e $6=$ base da muda totalmente podre, ocorrendo morte da planta. No segundo ensaio, quando se procurou avaliar o tempo necessário para que cada isolado provocasse os sintomas da doença em mudas da cv. Pérola, as avaliações foram efetuadas a cada 15 dias, anotando-se a expressão dos sintomas externos, observandose seca das folhas basais, clorose foliar, morte da muda, exsudação de goma, lesão local na inoculação, e adotando-se um sistema de escala de notas de 1 (um) a 4 (quatro), onde, $1=$ ausência de sintoma, $2=$ clorose foliar, 3= exudação de gomas e 4 = mudas mortas. Os ensaios foram repetidos sendo obtido resultados semelhantes. As cultivares 'Pérola' e 'Primavera' apresentaram comportamento diferenciado. Verificou-se que, quanto ao tamanho de lesão, o isolado E272 foi o que causou lesão de maior tamanho em mudas da cv. 'Pérola', seguido pelo isolado E290 embora não diferissem a $5 \%$ de probabilidade. Os isolados E283 e E278 diferiram dos demais e foram os menos virulentos. Em posição intermediária situaram-se os isolados E274, E279, E285. A cv. Primavera não mostrou reação visível a qualquer dos isolados testados (Tabela 1). Em se tratando do tempo para que cada isolado do fungo manifestasse sintomas da doença, verificou-se que o isolado E272, resistente ao benomyl, produziu exudação e causou morte das mudas aos 15 e 30 dias, respectivamente. Para os isolados E277 e E278 (sensíveis ao benomyl), observou-se morte das mudas aos 75 dias após o início do teste. Todos os isolados sensíveis ao benomyl só causaram os primeiros sintomas da doença aos 45 dias da inoculação (Tabela 2). Portanto, ficou comprovado que houve diferenças quanto ao comportamento dos isolados testados no tocante ao tempo em que cada um levou para causar a morte das mudas. Na cv. Primavera, observou-se apenas um leve escurecimento no local da inoculação, provavelmente devido a injúria causada pelo ferimento realizado para a inoculação, não ocorrendo colonização dos tecidos. Na avaliação final, os resultados demonstraram que 
